\title{
Electronic document flow as evidence in civil proceeding: evaluation features and application problems
}

\author{
G.V. Stankevich ${ }^{1 *}$, I.M. Vilgonenko ${ }^{2}, Y . N$. Slepenok ${ }^{4}$ and O.M. Litvishko ${ }^{3}$ \\ ${ }^{1}$ Pyatigorsk State University, Pyatigorsk, Russia; Stavropol Branch of Moscow State Pedagogical University, Stavropol, Russia, \\ stankevichg@rambler.ru \\ ${ }^{2}$ Pyatigorsk State University, Pyatigorsk, Russia, vil-irina-m@yandex.ru \\ ${ }^{3}$ Institute of Service, Tourism and Design (Branch) of North-Caucasus Federal University in Pyatigorsk, Pyatigorsk, Russia, \\ slep.80@mail.ru \\ ${ }^{4}$ Pyatigorsk State University, Pyatigorsk, Russia, olitvishko@yandex.ru
}

\begin{abstract}
Due to the development of information technologies, electronic document flow is actively becoming a part of modern life, and the activity of courts is not an exception. Electronic documents are increasingly considered by courts as evidence in civil cases. Judicial practice faces certain problems when evaluating such evidence due to the insufficiency of legal regulation of such kind of evidence. The article examines the theoretical and practical aspects of the existence of an electronic document as a type of written evidence, attempts to reveal the essence of an electronic document, define its features as compared to a traditional written document, and analyzes the approaches to the definition of the concept of 'electronic document', which have developed in Russian legal science. The analysis of the practice in the application of an electronic document as evidence with regard to relevance, admissibility and adequacy is carried out. Certain problems which judges have to face when using an electronic document as evidence have been identified. The authors' understanding of an electronic document is submitted, the framework of problems and gaps under current civil procedure legislation is defined, and methods of solution are proposed. The need to define an independent type of evidence - electronic evidence is substantiated, with it further being enshrined in the Civil Procedural Code of the Russian Federation, as well as to formalize in legislation the concept of an 'electronic information medium'.
\end{abstract}

\section{Introduction}

The era of digitalization of the Russian society and state should begin to run from the date of enactment of the Executive Order of the RF Government of 28.07.2017 No. 1632-R that approved the Program of "The Digital Economy of the Russian Federation"[1], which is part of the Strategy of the development of information society in the Russian Federation for 2017-2030, approved by Russian Federation Presidential Decree of 09.05.2017 No. 203 [2]. The ensuing amendments affected all areas, including the judicial system. The amendments made to the current civil procedure legislation of the Russian Federation in 2016, which came into legal force in 2017, enshrined the use of electronic document flow when applying to judicial bodies. However, the legislator did not extend the electronic (digital) document flow to the institute of evidence in civil proceedings, confining itself to mentioning in Part 1 Article 71 of the Civil Procedural Code of the RF (hereinafter CPC RF) that written evidence is represented by documents and materials executed in the form of digital, graphical record, including received via facsimile, electronic or other means of communication with the use of information and telecommunication network "Internet", as well as documents signed by an electronic signature. Thereby, the legislator has recognized the existence of such evidence as an electronic (digital) document, but does not regard it as the original, since Part 2 of Article 71 of the CPC RF binds litigants to submit copies of electronic documents in the form of an original, despite the fact that a copy of an electronic document is essentially the original of an electronic document. Thus, the legislator regards an electronic (digital) document not as an independent type of evidence, but as a type of written evidence, defying its specific character and features of electronic (digital) information exchange. This fact demands analyzing recent developments and substantiates the relevance of the conducted research [3].

\section{Problem Statement}

The main problem of the research consists in the fact that the current civil procedure legislation considers both a written document in its traditional form and an electronic

\footnotetext{
* Corresponding author: stankevichg@rambler.ru
} 
(digital) document as single-type phenomena. However, electronic document flow operates through electronic interaction of litigants in civil proceedings by means of information and telecommunication network "Internet" and the official website of the court. Following the implementation of the provisions of the Strategy of the development of information society in the Russian Federation, a system of such interaction has been established. One of the elements of this system, for instance, is information resource Gosulugi.ru (Integrated portal of state services), on the website of which various state services are provided online serving as an alternative to the MFC (Multifunctional centre), and thus performing electronic (digital) document flow. Should any civil disputes arise electronic (digital) documents sent and received within the framework of such interaction represent nothing more than electronic evidence of certain legal facts. With no registration on the website mentioned above, it is impossible to use the resources of the official site of the court when submitting such documents as a statement of claim and its appendices.

As a result, we witness the following situation: electronic (digital) document flow operates successfully, but the documents circulating within its framework and prepared in accordance with the requirements of the current legislation, do not have sufficient legal force to be considered as an independent form of evidence in a civil dispute, as providing their being submitted in electronic form, the judge may request them in the original, which complies with the norms of civil procedural legislation (Paragraph 2 of Article 71 of the code of CPC RF). Obviously, the legislator expresses a reservation in regard to the situations which demand the submission of original documents to the court alongside with those submitted in electronic form, but in general, we observe a situation in which civil procedural norms do not make allowance for the features of electronic (digital) information exchange and do not take into account the essence of an electronic document, especially the fact that in some civil cases an electronic document can act as the only evidence.

\section{Research Questions}

Having regard to the above, it is necessary to inquire into the essence of an electronic (digital) document, its evidential force and place in the system of evidence in civil disputes, to reveal the features of the assessment by the court the submitted electronic documents and to identify the problems that arise in the framework of law enforcement, which are faced by litigants in civil proceedings.

\section{Purpose of the Study}

Research of electronic (digital) documents as evidence in civil proceedings, identification of features of their assessment and problems of application in the practice of Russian courts in civil proceedings.

\section{Research Methods}

Research methods include general scientific methods of cognition (dialectics, synthesis; analogy; functional analysis) and specific legal methods: formal-legal, formal-dogmatic, comparative-legal, technical-legal, etc.

\section{Findings}

In order to achieve the goal set, it is necessary to refer to the legal framework of electronic (digital) document flow in the system of justice. In addition to the abovementioned CPC RF, the framework also includes: Federal law No. 149-FZ of 27.07.2006 "On information, information technologies and information protection" [4], in which Paragraph 11.1 of Article 2 provides the following definition of an electronic document documented information presented in electronic form, i.e. in a form suitable for human perception with the use of electronic computers, as well as for transmission via information and telecommunications networks or processing in information systems; Order of the Judicial Department of the Supreme Court of the Russian Federation No. 251 of 27.12.2016 "On approval of Procedure for submitting documents in electronic form to Federal courts of general jurisdiction, including in the form of an electronic document" [5], which establishes the official definition of an electronic document - a document created in electronic form with no prior documentation as hard copy, signed with an electronic signature in compliance with the legislation of the Russian Federation. In Paragraph 1.4 of the Procedure, the understanding of an electronic image of a document is also formulated, which is regarded as "an electronically-scanned copy of a paper document certified, in compliance with the Procedure for submitting documents, by a basic electronic signature or an enhanced encrypted and certified digital signature". Similarly, Order of the Judicial Department of the Supreme Court of the Russian Federation No. 252 of 28.12.2016 "On approval of Procedure for submitting documents in electronic form to the arbitration courts of the Russian Federation, including in the form of an electronic document" [6] and the Order of the Judicial Department of the Supreme Court of the Russian Federation No. 168 of 11.09.2017 "On approval of the Procedure of submitting documents in electronic form to magistrate judges, including in the form of an electronic document" both make distinction between an electronic document and an electronic image of a document [7].

The analysis of the aforementioned norms of the Russian law leads us to the conclusion that the current legislation and regulatory enforcement presume from the interpretation of an electronic document as written evidence created by a person and representing certain information medium relevant for the civil dispute under consideration, created with the use of modern information technologies, but capable of existing as hard copy, which in turn acquired the image of an electronic document by means of scanning. 
As we can see, the legislator regards an electronic document as written evidence, but the science of procedural law has developed the following approaches to understanding the essence and meaning of an electronic document in the system of evidence.

Thus, A.T. Bonner in the monograph "Traditional and non-traditional means of evidence in civil and arbitration proceedings" concludes that "it is unlikely that electronic documents can be automatically considered equivalent to traditional written documents, neither other modern sources of information - to material evidence" [8]. As an electronic document, the researcher regards a body of data in computer memory intended for human perception with the use of appropriate software and hardware, as well as the absence of copies of an electronic document, all copies of which are originals and have equal legal force [8].

A.P. Vershinin in his work "Electronic document: legal form and evidence in court" asserts that an electronic document does not possess one of the main attributes of written evidence, namely an external written form [9]. In his opinion, the material form of the medium of written evidence is secondary. The primary thing is that a written document transfers information by means of written signs which are voluntarily perceived by a person through reading or by ear [9]. This fact is also pointed out by Article 181 of the CPC RF, according to which written evidence is pronounced before the court in session and presented to parties to a case for review.

An electronic document is substantially different from a traditional document in the following ways:

- an electronic document is placed on an electronic medium (hard disk, flash card), it should be borne in mind that the same document can be placed on different media, while preserving the equivalence of the content and in this case remaining the original, not a copy;

- in order to be used as evidence, it must be converted to a format suitable for reproduction;

- it is generated, altered, transferred, stored owing to electronic document flow;

- it is certified by an electronic signature in the manner prescribed by the law;

- its contents must be identified.

For the purpose of using an electronic document as evidence, it must be converted into a form that allows litigants in the process to study its contents, namely, it should be printed out. From this point on, it ceases to be an electronic document, being transformed into a traditional document, but loses many of its properties. A traditional document does not contain information about who created the electronic document and when, what amendments and additions were made to it, etc. Thus, the printed version of an electronic document transfers only its contents in the latest version. An electronic document as a medium of information once encased on an electronic medium and reproduced with the use of a computer carries the full version of its existence, even if it was later deleted, but this data are rarely accessed, particularly as for these purposes it demands to involve specialists and use special means and software technologies. In practice, the final version of an electronic document serves most often as the means of evaluation, and it is this version in the traditional form that is taken cognizance of by the court. However, there may be situations which require the use of specialized methods to evaluate an electronic document, for instance, in cases of consumer protection when conducting cashless payments by means of electronic money, disputes with credit organizations related to opening transaction accounts, deposits, obtaining loans, etc.

An electronic document is a distinctive type of evidence which has its own merits and demerits. Like any media, it may contain false information, in particular, if it is entered negligently. Therefore, it must be evaluated as one of the facts in evidence with no preference over other facts in evidence.

In the practice of courts with regard to an electronic document, difficulties may arise related to the application of provisional measures, for example, when protecting copyrights on created computer programmes or databases.

In particular cases, the evaluation of an electronic document may demand conducting technical expert examination on the motion of the parties, since such electronic medium can also be falsified using special software. An example of such disputes is the protection of patients' rights - a medical report signed by an unauthorized person, laboratory tests are not factually accurate and the patient suffers injuries to health, etc.

One of qualificatory features of an electronic document is its authentication and identification. Only an electronic signature can be used in the process of authentication and identification of an electronic document [10]. In court practice, situations may arise related to confirming the existence of a digital signature, since only a text is visualized in the electronic document flow. By Order of Rospatent No. 57 of 13.04.2016 (ed. 28.07.2016) "On establishing[11]. The rules and Form of visual display of an electronic signature mark on documents in electronic form" this problem is solved as follows: the rules for visualizing the electronic signature on documents have been developed and the form for visual display of the electronic signature mark has been approved, still some authors believe that the legal effect of such document is void [12].

Therefore, when evaluating an electronic document, the court must first of all proceed on the basis of the triad of evidence evaluation: relevance, admissibility and adequacy of evidence. Consequently, electronic documents being served in violation of the current legislation cannot be accepted for consideration, that is, they are recognized as inadmissible.

\section{Conclusion}

The conducted analysis allows us to formulate the following conclusions.

It is necessary to agree with the conclusions of scholars who conducted research into features of electronic justice in Russian judicial system. They state 
that the introduction of modern information technologies will increase the standards of legal proceedings, their quality, speed up the process of resolving disputes on the merits, simplify document flow and clerical correspondence in courts, and increase citizens' confidence in justice [3].

We propose to understand an electronic document as a document that appeared in the process of electronic document flow, and certified by an electronic signature.

The features of an electronic document do not allow it to be recognized as identical to a traditional document, and it is considered inexpedient to extend the legal regime of the latter to an electronic document.

So far, an electronic document has not been governed by the civil procedural legislation of the Russian Federation.

An electronic document should be regarded as a type of written evidence.

Judicial practice on the assessment of an electronic document as evidence is based on the content of Article 6 of the Federal law No. 63-FZ of 06.04.2011 "On electronic signature" [14] and recognizes it as equivalent to a hard copy document signed with a handwritten signature.

A range of urgent issues related to the use of an electronic document as evidence in a civil case should include the following:

- Its assessment may demand using special methods, software and involvement of experts, as well as conducting technical expert examination.

- It is difficult to provide interim measures.

- Problems may arise in confirming the existence of an electronic signature or its validity, since the visual image of an electronic signature does not represent the electronic signature itself.

- To overcome the highlighted problems, we consider it reasonable to make the make the following amendments to the current legislation:

- To amend Chapter 6 of the Civil Procedural Code of the Russian Federation by enshrining electronic evidence as a separate type of evidence.

- To supplement the provisions of Article 2 of Federal law No. 149-FZ of 27.07.2006 "On information, information technologies and information protection" with the concept of "electronic information medium"[15].

\section{References}

1. Decree of the Government of the Russian Federation No. 1632-R of 28.07.2017 "On approval of the Program of digital economy of the Russian Federation" / Expired.

2. Decree of the President of the Russian Federation No. 203 of 09.05.2017 "On the Strategy of the development of information society in the Russian Federation for 2017-2030".

3. Procedure for submitting documents to the arbitration courts of the Russian Federation in electronic form, including in the form of an electronic document".
4. Federal law No. 149-FZ of 27.07.2006 "On information, information technologies and information protection

5. Order of the Judicial Department of the Supreme Court of the Russian Federation No. 251 of 27.12.2016 "On approval of the Procedure for submitting documents to Federal courts of General jurisdiction in electronic form, including in the form of an electronic document".

6. Order of the Judicial Department of the Supreme Court of the Russian Federation No. 252 of 28.12.2016 "On approval of Procedure for submitting documents in electronic form to the arbitration courts of the Russian Federation, including in the form of an electronic document".

7. Order of the Judicial Department of the Supreme Court of the Russian Federation No. 168 of 11.09.2017 "On approval of the Procedure for submitting documents to magistrate judges in electronic form, including in the form of an electronic document".

8. A.T. Bonner, Selected works: in 7 v. V. 5. Problems of the theory of forensic evidence (Moscow, Russia: Prospekt, 2017).

9. A.P Vershinin, Electronic document: legal form and evidence in court (Moscow, Russia: JSC "GorodetsIzdat", 2000)

10. Zubov, V.V. (2020). Electronic signature in the digital economy. DOI: 10.15405 / epsbs.2020.03.89.

11. Rospatent Order No. 57 of 13.04.2016 (ed. of 28.07.2016) "On approval of the Rules and Form for visual display of the electronic signature mark on documents in electronic form".

12. N.A. Hramtsovskaya, Electronic signature visualization: domestic and foreign approaches. Office and document management at enterprise, 12. (2014), URL: https://www.eos.ru/upload/analitica/Delo_201412\%2002.pdf. (date of access: 16.03.21).

13. A.V. Azarkhin, D.A. Karev, A.A. Petrogradskaya, Electronic justice in the courts of the Russian Federation (2020)

14. Federal law No. 63-FZ of 06.04.2011 "On electronic signature".

15. Federal law No. 149-FZ of 27.07.2006 "On information, information technologies and information protection 